\title{
A AULA COMO GESTO: um princípio para a docência
}

Cristiano Bedin da Costa

Angélica Vier Munboz.

Resumo

O artigo defende um princípio comum para a formação docente, caracterizado por uma lógica relacional que articula as diferentes personagens da cena didática. Três modos de existência da aula são propostos, para assim definir o que se denomina espaço potencial, entendido como a dimensão criadora que envolve virtualmente a relação pedagógica. Nomes como Walter Benjamin, Paul Valéry, Andy Warhol, Giorgio Agamben, Vilém Flusser e Roland Barthes são mobilizados a fim de teorizar o gesto como gênero de ação vinculado à abertura de um espaço onde o não-previsto ganha corpo. As discussões encaminham-se para a defesa da aula como um lugar em suspenso, no qual a docência é relacionada ao trabalho de sustentação de uma experiência singular de tempo e espaço.

Palavras-chave: gesto; docência; aula

THE CLASS AS GESTURE: a principle for teaching

\begin{abstract}
The article defends a common principle for teacher education, characterized by a relational logic that articulates the different characters in the didactic scene. Three modes of class existence are proposed, in order to define what is called potential space, understood as the creative dimension that virtually involves the pedagogical relationship. Names such as Walter Benjamin, Paul Valéry, Andy Warhol, Giorgio Agamben, Vilém Flusser and Roland Barthes are mobilized in order to theorize the gesture as a genre of action linked to the opening of a space where the unforeseen takes shape. The discussions are directed towards the defense of the class as a suspended place, in which teaching is related to the work of sustaining a singular experience of time and space.
\end{abstract}

Keywords: gesture; teaching; class

\section{LA CLASE COMO GESTO: un principio para la enseñanza}

Resumen

El artículo defiende un principio común para la formación del profesorado, caracterizado por una lógica relacional que articula a los diferentes personajes del escenario didáctico. Se proponen tres modos de existencia en la clase, con el fin de definir lo que se denomina espacio potencial, entendido como la dimensión creativa que involucra virtualmente la relación pedagógica. Nombres como Walter Benjamin, Paul Valéry, Andy Warhol, Giorgio Agamben, Vilém Flusser o Roland Barthes se movilizan para teorizar el gesto como un género de acción vinculado a la apertura de un espacio donde lo imprevisto toma forma. Las discusiones se dirigen hacia la defensa de la clase como un lugar suspendido, en el que la enseñanza se relaciona con el trabajo de sostener una experiencia singular del tiempo y del espacio.

Palabras clave: gesto; enseñanza; clase 


\section{Para sublevar o mundo, são necessários gestos, desejos, profundezas (Georges Didi-Huberman)}

\section{UM PRINCÍPIO COMUM}

Comecemos com um diagnóstico.

Há quase um século, a análise de Walter Benjamin sobre o moderno indicava que a pobreza do vivido não necessariamente está ligada à sua carência, significando também sobrecarga e saturação. Afetada de modo incessante por diversas ordens de estímulos em um mundo materialista e mecanizado, a humanidade via surgir diante de si uma forma de miséria até então inédita, signo do automatismo de um estilo de vida conduzido por leis que já não conseguia controlar. Nascia "uma nova barbárie" (BENJAMIN, 1994, p. 115), caracterizada pela crença de superação da pobreza cultural pela novidade, pela busca cega de vivências sempre veementes, pelo tédio próprio do novo transformado em rotina. O bárbaro solapa o tempo da percepção, da avaliação e do cuidado, atitudes indispensáveis à conversão do vivido em experiência, isto é, à sua tradução em um saber viver.

Experiências são vestígios, tal como sugere a síntese proposta por Olgária Matos (2013), aqui assumida como princípio argumentativo. Traços de tempos heterogêneos que permanecem na memória inconsciente, onde se aloja a aura do tempo. Lembremos que a noção de aura em Benjamin está relacionada com a autenticidade e a unicidade, de modo que sua existência consiste na "[...] aparição única de uma coisa distante, por mais perto que ela esteja" (BENJAMIN, 1994, p. 170). Uma autêntica experiência do tempo marca o aqui e agora como instante singular e irrepetível. Por outro lado, uma temporalidade sem aura é um intervalo qualquer em uma contagem impessoal. A aura do tempo é feita de presentes de encarnação (PENNAC, 1993), instantes em que o corpo e a alma coagulam-se com o mundo. Eis por que a aceleração do tempo e o correlato desmoronamento da experiência representam a comoção da tradição e tornam banal o esquecimento do passado recente.

Talvez estejam na sonoridade das canções de ninar os nossos primeiros vestígios. Porque "[...] a delicadeza é a matéria desses cantos, seus versos breves possuem a potência miraculosa de metamorfosear angústias e desejos em sono e sonho" (MATOS, 2013, p. 103). O zelo e o cuidado sonoro da canção dão carne e unidade ao corpo fragmentado que chora, pavimentam um território existencial, compõem um primeiro refrão para o qual se faz possível retornar. A voz que embala e canta marca o tempo de uma primeira experiência ética, fundamenta uma necessária arte de viver. O tempo longo desse cuidado é de um encontro entre o que foi, o que é e o que será, um laço estabelecido entre a infância e a vida adulta, o presente e passado de quem cuida e a potência da vida que se inicia. Uma canção de ninar é o esboço de um centro estável, ao redor do qual a voz e a escuta constituem um corpo comum. O eu começa no cantar, por uma cadência sussurrada, por um ritmo cuja duração suspende o que está do lado de fora. De um modo ou de outro, esse halo protetor não deixará de acompanhar a vida que ele ajuda a sustentar e a delinear.

Entendemos a experiência como uma espécie de transcendência histórica. Alguma coisa em alguma vida que resiste, certa vivência individual que devém forma independente de vida, ou seja, articula-se a partir de um saber passível de ser legado, transmitido de geração em geração, através do tempo. Assim como uma mãe que ao envolver seu bebê em uma melodia também está vinculada ao canto anterior que a amparou até ali, a experiência é atualizada pela vida que a recebe, já que a cada vez é articulada a outros vestígios. O vivido é sempre efêmero, mas há algo na 
experiência do tempo que pode esboçar uma memória corporal, que subsiste a cada existência que a encarna e a dramatiza.

A experiência é um saber do corpo, e é nesse sentido que Benjamin não vê com estranheza o fato de os combatentes voltarem da grande guerra mais pobres em experiências comunicáveis, e não mais ricos. Frente a um dos mais terríveis acontecimentos da história, toda estratégia de sobrevivência é desmoralizada pelas trincheiras, pela fome.

Uma geração que ainda fora à escola num bonde puxado por cavalos viu-se abandonada, sem teto, numa paisagem diferente em tudo, exceto nas nuvens, e em cujo centro, num campo de forças de correntes e explosões destruidoras, estava o frágil e minúsculo corpo humano (BENJAMIN, 1994, p. 115).

A guerra é sempre real, e seu peso está acima de toda capacidade de significação. Não há rastros em um campo de batalha, apenas corpos mortos, iguais, sem vestígios do que um dia foram. Em tal paisagem, o futuro se mostra como todo o resto, na medida em que já não pode ser pensado e reconhecido da mesma maneira. Trata-se de um futuro saturado de uma realidade cujo principal efeito é aniquilar todas as esperanças presentes, isto é, um futuro que é o tempo e o lugar do fim das utopias.

Presente, passado e futuro formam uma trama indissociável. Nenhuma imagem de futuro é possível sem a lembrança de algum passado e a percepção crítica do presente. O olho que vê é um olho marcado, carregado, feito de vestígios que tanto subsistem quanto antecipam. Ver é rever e prever, na medida em que as imagens do passado refletem sobre a revelação do que ainda não existe, do futuro que se insinua de modo sensível no instante, pressionando-o.

O exercício do pensamento é a força capaz de interromper o fluxo contínuo do tempo histórico (ARENDT, 1979). Porque o apelo ao pensamento se dá em um entre-dois determinado por aquilo que não mais existe e aquilo que não existe ainda. Pensar é situar-se entre dois mundos, inserir um instante de tempo entre passado e futuro, ocupar um intervalo temporal ainda em aberto, cujo enigma cabe ao pensamento desvendar. Pensa-se justamente nessa lacuna onde o fluxo indiferente do tempo parte-se em passado, presente e futuro, ou seja, o ponto no qual as forças advindas do passado e do futuro se chocam, desviando mesmo que ligeiramente de suas direções originais, constitui o princípio do pensamento. Passado e futuro determinam sua direção, o sentido de sua força, mesmo que seu destino permaneça em aberto.

Façamos agora um deslocamento espaço-temporal.

A cultura de vidro cujo surgimento é diagnosticado por Benjamin recebe de nosso tempo uma nova concessão para existir. O espaço de hipermobilidade (SANTAELLA, 2007) que caracteriza a contemporaneidade, forjado pela fusão dos deslocamentos online e off-line, determina uma nova ordem de vestígios. Nada parece feito para durar, tudo aparenta estar envolto por certo distanciamento e frieza. Modas rápidas, conexões rápidas, leituras e lições rápidas e fáceis: a velocidade como signo de um mundo tão instantâneo quanto não aderente, um mundo repelente aos rastros.

Mesmo marcando uma suspensão sem precedentes para relações sociais e educativas, o "parar pandêmico" (ZORDAN, ALMEIDA, 2020) e os protocolos de segurança relativos ao enfrentamento do novo coronavírus (Sars-Cov-2) não inauguram, mas evidenciam uma realidade que sob vários aspectos já estava dada. Tal como fizeram os experimentos fotográficos de Muybridge, a pandemia escancara a trama de microações que constitui nossos atos mais triviais, além de tornar dramaticamente evidente e compulsória a erosão do outro e de seus vestígios, pelo solapamento do tempo que abarca seu corpo e seu ritmo. De modo sorrateiro, diferentes âmbitos 
de nossa vida vão gradativamente se despedindo do outro e se fechando para o que não pode ser abarcado pelo regime igualitário do eu (HAN, 2017).

No contexto recente das pesquisas em educação, estudos como os de Aquino (2017), Pisetta (2019) e Nóvoa (2019) apontam pra a necessidade de pensar a relação pedagógica a partir de uma perspectiva não apenas praticista e acrítica, de modo que os lugares de docência e discência sejam tomados em sua dimensão relacional e de coimplicação. No limite, trata-se de perspectivar a experiência da aula como a ocasião de uma temporalidade particular, marcada pelo encontro e o tensionamento de corpos em relação.

Diante de um presente balizado pela mobilização infinita e de um futuro que não é mais o que era, quais são os sentidos possíveis de uma aula, enquanto ação que se desenvolve entre tempos de perda, de espera e de incertezas diversas?

Tendo como propósito pensar a experiência da aula no âmbito da formação de professores, o presente artigo vincula a ação didática a um compromisso que não é apenas de ensino (no sentido simples de transmissão de conhecimento), mas também de sustentação do que nomeamos princípio formativo do comum. Como princípio formativo, o comum exige que a participação na aula seja o fundamento da obrigação educacional, portanto que a coatividade seja o fundamento da coobrigação. Disso resulta que nenhum pertencimento - gênero, raça, curso, formação, etnia, classe social etc. - pode ser em si o fundamento da obrigação educacional. Disso resulta também que essa obrigação não tem nenhum caráter institucional, o que implica que qualquer fonte transcendente e autoridade exterior à aula devem ser rejeitadas. A obrigação educacional procede inteiramente do agir comum, "[...] extrai força do compromisso prático que une todos os que elaboram juntos as regras de sua atividade, e vale apenas para os coparticipantes de uma mesma atividade" (DARDOT, LAVAL, 2017, p. 617).

O que participar quer dizer? $\mathrm{Na}$ medida em que o comum é o princípio formativo que rege a atividade educacional, a participação está vinculada à deliberação coletiva daquilo que a aula, entendida como espaço-tempo efetivo de trabalho, desejará produzir. Perspectivar a formação pelo princípio do comum significa que a docência compreende o estabelecimento do vínculo, a consideração do outro, a constituição de zonas de intensidades diferentes na aula. O princípio formativo do comum não é um bem ou conhecimento que possa e deva ser transmitido, mas sim uma imagem de pensamento que fundamenta a totalidade das práticas de ensino e aprendizagem. De acordo com tal princípio, uma aula terá tanto uma dimensão individual, ligada ao modo como cada participante irá se vincular com aquilo que ela dá a faz̧er, quanto outra coletiva, mobilizadas pelas relações das quais ela é cenário. Acreditamos não haver hierarquia entre elas, o que significa jamais subordinar o coletivo ao individual.

Buscaremos a seguir desenvolver teoricamente a relação entre o princípio formativo comum e a prática docente, articulados na experiência da aula. Partimos da hipótese de que a especificidade da aula consiste em um modo singular de relacionar o corpo e o pensamento a dinamismos espaçotemporais particulares. Neles, o corpo confunde-se com o gesto, unidade analítica aqui privilegiada. Pela dimensão gestual do corpo, pelo modo como suas ações recortam o tempo e o espaço, uma experiência singular e comum é construída. Cabe à docência sustentar tais movimentos, criando estratégias didático-relacionais para isso.

Mais do que se responsabilizar pela ordem institucional, a docência está empenhada no cuidado de uma zona comum de estudo, assimilação crítica e autoatualização (HOOKS, 2017). A aula como lugar e tempo de experiência, da inscrição de uma singularidade, ou seja, a marca de uma assinatura. 
Iniciaremos discutindo os diferentes modos de existência da aula, para assim definir o que denominamos zona de instauração ou espaço potencial, relacionado à dimensão criadora que envolve virtualmente toda relação pedagógica. O pensamento do informe de Paul Valéry e a arte mecânica de Andy Warhol serão nossos principais intercessores. Em seguida, iremos mobilizar as proposições sobre o gesto feitas por Giorgio Agamben e Vilém Flusser, de maneira a relacionar o potencial criador da aula a um espaço de atuação no qual o corpo desdobra-se em uma existência livre dos limites institucionais. Por fim, ao modo de conclusão, defenderemos a docência como uma prática cuja dimensão estético-política está relacionada ao gesto de sustentação de uma experiência particular e significativa com o tempo e o espaço.

\section{MODOS DE EXIST'ÊNCIA DA AULA}

Acreditamos ser possível pensar a aula e o trabalho de formação como práticas manuais. A mão como "[...] o órgão por excelência do fazer, o índice mesmo da humanidade" (REY, 1994, p. 151). A mão docente esboça e traça, assim como lê, desenha, molda e desfaz.

Faz isso com o quê? Antes de tudo, com seu pensamento a respeito da aula, ou seja, com o modo como executa uma tarefa que pode realizar de inúmeras maneiras. Porque uma aula é antes estudo, pesquisa, isto é, formação. É no decorrer de tais movimentos que pode advir a ideia e, com ela, o plano didático.

A mão destaca, seleciona. A mão monta, estabelece proximidades, lança propostas. Faz isso e, também, ajusta, aparta, dita o ritmo, retém e restitui. Pela mão, a docência se define pelas conexões que inventa. Sobretudo, define-se pelo que pode sustentar. Manual, a aula reside inteiramente em seu ato, ou seja, é matéria maleável, suscetível de ser modelada e desfeita, opondose a tudo que já está formado e acabado. Espaço e tempo de gestos múltiplos, uma aula é também uma ocasião de encontro entre a ideia abstrata e a realidade concreta, a junção entre a ordem das coisas sensíveis e inteligíveis.

Em seus ensaios a respeito da poética de Leonardo da Vinci e de Edgar Degas, Paul Valéry (1998; 2013) defende o trabalho de reflexão do artista, caracterizado pela atenção ao intercâmbio íntimo entre a matéria e o espírito, entendido como potência de criação e transformação. Tal esforço é sempre dirigido ao processo, ao movimento que parte do não-significativo e inventa roteiros rumo à significação. Nele, o gesto poético, sempre múltiplo, impõe-se à obra, pois traça um espaço potencial de pensamento e experimentação, aberto ao possível. É disso que nos lembra Valéry (1998), ao mencionar o esquecimento que envolve toda obra, e que é responsável por desconsiderarmos a ação que a trouxe até nós, ou seja, é responsável pela ignorância dos meios, dos exercícios, do fazer em si. Diferente da percepção ordinária, a reflexão-artista é um pensamento sobre esse fazer, um voltar-se para o gesto.

Tomemos o exemplo de um exercício pelo informe, apresentado por Valéry em Degas Dança Desenho: o artista está diante de um pedaço de tecido jogado sobre uma mesa. O objeto não se assemelha a nada, é uma desordem de dobras. Ele mexe em suas pontas, revira-o, e isso não causa nenhum prejuízo à sua forma não estruturada. Seu problema é fazer ver, por meio da forma de expressão utilizada, "[...] um pedaço de tecido de determinada espécie, maciez e espessura, e constituindo uma peça única" (VALÉRY, 2013, p. 80). Trata-se de dotar de inteligibilidade uma existência não redutível a uma lei única de visibilidade e que não é outra coisa senão uma possibilidade. É nesse ponto que o artista, frente a uma mera sugestão, exerce sua inteligência, e que seu olho deve encontrar, por seu movimento sobre o que vê, " $[\ldots .$.$] os caminhos do lápis sobre$ 
o papel, como um cego deve, apalpando-a, acumular os elementos de contato de uma forma, e adquirir ponto por ponto o conhecimento e a unidade de um sólido muito regular".

Esses exercícios pelo informe ensinam a atenção para as presenças singulares, os modos de existência anteriores a todas as formatações e substituições imediatas que a educação mais elementar nos inculcou.

O informe "[...] nada mais é do que essa ação de começar pelo começo, por um ponto de partida não-significativo da percepção, pelo qual se apreendem fenômenos ainda não interpretados; sentidos não atribuídos; valores não acrescentados" (CORAZZA, 2012, p. 89). No que diz respeito ao trabalho da aula, parece-nos que tal exercício pode estar vinculado ao esforço de encontrar, a partir dos gestos mínimos e até insignificantes, a singularidade dos olhares, das mãos, do corpo e de seu desejo. Tal esforço certamente parte da docência, mas não se reduz a ela. $\mathrm{Na}$ medida em que a aula é vivida como uma experiência relacional, seu princípio comum faz com que esse movimento em direção ao não-sentido seja uma tarefa coletiva.

Vejamos como isso pode ocorrer. Para tanto, articulemos ao pensamento valeryano do informe a arte mecânica de Andy Warhol. É desse encontro que iremos retirar certa ideia de aula que aqui nos interessa pensar.

Durante os anos de 1978 e 1979, Warhol produz Shadows, obra concebida como uma única pintura dividida em 102 partes. A partir de uma série de fotografias realizadas em seu estúdio lembremos que o órgão do fotógrafo não é apenas o olho, mas também o dedo, enquanto operador do instante, tal como sugerido por Roland Barthes (1984) -, Warhol cria as telas por meio de serigrafia. Uma a uma, manualmente, as imagens ganham forma. Mesmo aparentando igualdade, variam em suas cores e nos detalhes produzidos no processo de impressão. Cada sombra é um gesto, e cada gesto produz uma peça única. É sua disposição sequencial, com os painéis de igual dimensão colocados lado a lado, que dá a ver a singularidade de suas partes, assim como a força diferencial que constitui a obra.

Central dentro da poética warholiana, a repetição não é artifício de reprodução, mas sim de desvio. O espírito autômato que conduz a produção de Shadows se manifesta por operações de seleção, apropriação e deslocamento. Repetir é deslocar, amortecer e fazer oscilar o sentido, e não copiar e fazer ressoar o mesmo. É isso o que sugere o famoso mote da persona de Warhol: "Não quero que seja essencialmente o mesmo - quero que seja exatamente o mesmo. Porque quanto mais você olha para a mesma coisa, mais o sentido se esvai" (WARHOL, HACKET'T, 1980, p. 50) ${ }^{1}$.

Ao contrário do exercício valeryano, a prática de Warhol não parte do informe, mas daquilo que já está dado e posto em circulação por uma sociedade de produção e consumo em série. As sombras, assim, vinculam o gesto à técnica de repetição que estabelece a condição para a experiência da obra.

Situemo-nos no meio do caminho, entre o movimento de uma força que parte da forma acabada em direção à sua dissolução e outra que parte do informe e quer dotá-lo de sentido. A aula é esse lugar.

Em um primeiro plano, a aula é um espaço institucional. Nele, o que vemos é uma cena conhecida: entrar em uma aula é ocupar um cenário já delineado, seguir marcações de um roteiro mais ou menos pronto, dentro de um tempo determinado. Conhecido também é o conflito que mobiliza as personagens e faz avançar a história: "O que está em causa em uma sala de aula são precisamente os embates narrativos típicos do encontro entre os mais velhos e os mais novos; nada

1 Tradução nossa do original: I don't want it to be essentially the same - I want it to be exactly the same. Because the more you look at the same exact thing, the more the meaning goes away. 
além” (AQUINO, 2019, p. 438). Papéis em um jogo cênico, o velho e o novo são posições discursivas, e não exatamente traços identitários. Uma aula é a ocasião em que uma voz anterior é sustentada e esforça-se para se fazer ouvir, testemunhar em defesa de certa imagem do passado no tempo presente. Nessa cena, sustentar e defender são atribuições docentes.

Deve-se sempre considerar a existência de "[...] uma força plástica que atravessa o ato docente" (AQUINO, CORAZZA, ADÓ, 2018, p. 14), materializada no arranjo curricular e na disposição didática, ouvida por meio de escolhas e estilo, pelo modo como a matéria que envolve seu fazer é trabalhada. Inicialmente solitária, essa voz, um pouco como a voz que escreve, é também "[...] o modo de quem tem a palavra como isca" (LISPECTOR, 1998, p. 21), a palavra que se projeta e busca o que não é palavra, a palavra que deseja fisgar a entrelinha, lá de onde advém a resposta como murmúrio ou estrondo.

A dimensão institucional da aula funciona como uma espécie de carta de intenções. Nela são manifestos os objetivos, o tempo e o método utilizados para alcançá-los. Uma aula é antes o estabelecimento de regras, a definição de posições e a fixação de uma periodicidade. O espaço da instituição é o espaço da lei. Longe de ser descartável, essa dimensão garante a aula como repetição e retorno, sustenta a relação intersubjetiva durante determinado tempo. Simbólica ou concreta, a instituição estabelece os reinícios. Há um dia após outro dia, uma semana que se desdobra em meses, os meses completando o semestre ou ano de trabalho.

Pensemos tais encontros como frisos dispostos em sequência, à maneira das sombras de Warhol. Na superfície de cada um deles, um conjunto singular de zonas de contato, nas quais estão inscritos os humores e os afetos, as atrações e repulsas, o campo magnético ao redor de cada gesto. Enquanto a instituição é o espaço das formas fixas (o lugar do eu, do nome, da norma), o corpo move-se pela superfície.

Não se trata de espaços opostos, o primeiro é condição de possibilidade para o segundo. À instituição cabe suportar os deslizes do corpo. A este cabe tonalizar aquela. Pensemos o exercício do informe como a atenção ao que Barthes (2004a, p. 412) chama "[...] topologia sutil das relações corporais", capaz de suceder a "geometria grosseira" dos grandes estratos compartilhados. A zona de contato superficial é um suplemento, um efeito derivado, produzido dentro dos limites instaurados pela regulagem institucional. O lugar do indireto, a dimensão onde o escoamento do saber esboça os contornos de outra forma de partilha, de outras cenas pedagógicas.

O que mostra esse modo de existência superficial da aula? No limite, que uma aula comporta sempre algo mais. Pode-se ou não considerar esse excesso, porém, parece-nos que é nele que tudo se decide, na medida em que ele comporta as potencialidades que envolvem cada aula, ou seja, aquilo que uma aula pode vir a ser, sem garantias de que será. A superfície não indica ausência de profundidade, mas sim espaço de contato. É sempre pela articulação entre o espaço institucional e o espaço superficial que uma zona de atualização de outros possíveis é traçada².

\footnotetext{
${ }^{2}$ Escrevemos este texto em um contexto pandêmico e durante a suspensão das atividades acadêmicas presenciais, ainda sem nenhuma previsão de retorno das mesmas. O modo como pensamos a aula, no entanto, segue abalizado pelo signo da presença física e da proximidade corporal. Não abordaremos aqui as consequências do ensino remoto para as relações sociais e educativas, tampouco iremos problematizar a pervasividade da tecnologia digital no contemporâneo. Longe de acreditar no fim da vida universitária e no “[...] fim do estudando como forma de vida", teses recentemente defendidas por Agamben (2020) no ensaio Réquiem para os estudantes, preferimos perspectivar a pandemia como um tempo de crise e passagem, na medida em que o saber docente necessariamente deverá ceder frente a novas formas de percepção e de ocupação do tempo e do espaço. Tais formas serão o que puderem ser, o que conseguiremos criar. A ideia de falta, portanto, não está incluída em tal perspectiva.
} 
Retomemos à imagem da mão e sua operacionalidade didático-formativa, pensemos sobre o ver e o traçar. De acordo com Valéry (2013, p. 69), “[...] há uma imensa diferença entre ver uma coisa sem o lápis na mão e vê-la desenhando". Desenhar é tanto um artifício háptico quanto óptico, na medida que o gesto da mão que desenha, ao desejar traduzir o visível em traço, cria uma nova superfície relacional. O movimento da mão ensina que o saber do corpo é outro em relação ao dos olhos, porque suprime a distância imposta pela visão. A mão confere ao olho uma outra potência, conduzindo-o através dos comandos de um querer ver. A observação é a criação de uma atenção voluntária e de uma correlata visão deliberada, um gesto através do qual a mão vê e traça linhas que são musculares, linhas esboçadas por um corpo que se comporta como acessório de seus olhos, um corpo que se contrai, avança e recua, torna-se por inteiro órgão de mira, aproximação, captura.

Tanto quanto é essencial ao desenho, esse desejo de querer ver é central à docência. Uma aula é feita de personagens independentes que estão sempre pedindo para resgatar lugares e automatismos que institucionalmente lhes são próprios. Diante disso, de que modo viver a aula como um espaço de aprendizagem constante do olhar, no sentido de acostumá-lo à distância e à lentidão, fidelizá-lo a uma visão corporal, que tateia e tem mãos para nuances? Poderíamos pensar uma formação não pautada por saberes externos, pelo previsível da instituição que media uma demanda do mundo, mas sim pela expectativa do novo, enquanto ainda não experimentado?

Uma sala de aula é uma "ocasião" (AQUINO, 2019, p. 435). Um espaço de choque e partilha, dentro do qual o outro nunca espera. É apenas em um nível institucional que se pode falar em um antes e depois. Na superfície, tudo o que há são atravessamentos, gestos, afetos imediatos, ressonâncias. $\mathrm{O}$ traçado de um espaço potencial é um exercício em meio a esse informe, o elogio de um pensamento muscular e de uma formação manual, orgânica, corporal. O que está em causa nessa dimensão da aula é uma experiência que pressupõe a assimetria e alteridade irredutível do outro (HAN, 2017), cuja presença instaura uma distância crítica entre as partes em relação. Sob a instituição, na tensão de sua superfície, uma aula é pura vulnerabilidade.

Podemos avançar nesse espaço ao modo de um leitor que rabisca nas margens de uma obra e produz, à força de seu querer ver, pequenos registros de leitura que são também indicações de percurso. E podemos também fazer desse texto segundo, dessa escrita superficial que se faz a cada retorno, dia após dia, um espaço para outras leituras, com outras margens para novas notas, feitas por aqueles com quem compartilhamos a experiência da aula. Podemos pensar a docência como leitura, avaliação e abertura de espaços. E, por extensão, podemos perspectivar a formação como a ocasião na qual esses espaços potenciais são traçados e habitados.

Aulas assim perspectivadas não encontram sentido em deveres que se voltam para fora, mas sim em suas obrigações mais íntimas. O que a aula torna possível encenar? Quais personagens a compõem? Qual experiência de tempo ela permite viver? Quais gestos a sustentam? Por quais vozes ela é expressa? Tais questões são princípios sempre retomados, e não há resposta capaz de evitar seu retorno. Há sempre algo mais a ser visto, há sempre algo aparecendo, desaparecendo, um novo início sendo esboçado.

Cada olhar, cada palavra, cada gesto pode funcionar como a condição de uma existência outra, o traçado de uma diagonal entre o dado e o potencial, o sensível e o inteligível. Portanto, trata-se de nossa própria vida docente, permanentemente esboçada, que cabe avaliar e distender, tal como um texto que se prolonga por suas margens.

\section{UM MEIO SEM FIM}

"A qualquer hora que você acordasse havia alguma porta batendo". 
A frase inicial de Casa assombrada, de Virginia Woolf (2008, p. 163), é também a porta de entrada em $A$ ghost story, de David Lowery. No filme, as personagens escrevem bilhetes que escondem pela casa, como modo de preservar pequenos pedaços de si. Trata-se de um exercício sobre o tempo, mais precisamente sobre o modo como nos inserimos nele.

Em toda vida, há pequenos gestos, ações aparentemente insignificantes, cujo sentido é tanto urgente quanto inapreensível, na medida em que a sustentam em segredo, silenciosamente. De certo modo, são gestos que dizem mais da vida do que do sujeito que a encarna, já que não deixam de se repetir e serem reencenados em outros contextos históricos. Uma fenda na parede, o espaço entre uma página e outra, uma grande pedra no gramado, são esconderijos nos quais a existência - e não apenas algum aspecto da existência - é sustentada por seus vestígios. A personagem M. anota fragmentos de textos, versos de poemas. Os manuscritos são feitos de leitura, palavras de outros tempos, vindas de instantes perdidos, espalhadas por aquele que agora é, e um dia não mais será, o território de sua vida. São batidas anônimas na porta. Não há nomes, não há autoria, apenas o texto que o espectador não lê. Não por acaso, são palavras escondidas em uma casa assombrada, e apenas sua leitura liberta a vida fantasma que a ela está presa de seu gesto repetido de busca. Testemunhamos o fazer e seus efeitos no tempo, o fazer e seus rastros. E isso é tudo. O gesto de escrever "[...] é uma maneira, simplesmente, de lutar, de dominar o sentimento de morte e abolição integral” (BARTHES, 2004b, p. 511). A mão que escreve modela o tempo de modo a sustentar nele a passagem de uma vida. Nada mais.

A história nos sugere algumas imagens. Elas nos ajudarão a perspectivar mais diretamente, a partir de agora, a aula por meio de um princípio gestual.

Dentro da ampla gama de atos humanos, existem alguns que não se deixam inscrever como ações que visem um fim específico. Ao contrário, parecem conter em si mesmo sua causa e destino, na medida em que não respondem a uma demanda de produção exterior e nem objetivam esgotarse em suas manifestações. Diremos, da esteira de Flusser (2014), que esses atos são movimentos nos quais se articula uma liberdade.

Não são movimentos livres, automáticos ou aleatórios, mas voluntários, nos quais a liberdade se expressa de alguma maneira. Tal grau de liberdade não representa outra coisa senão a impossibilidade de determinar, de forma exaustiva, a razão de sua existência. Por exemplo: o ato de cozinhar pode ser explicado por uma necessidade fisiológica ou profissional, e tem no alimento preparado o seu fim. No entanto, se considerarmos os modos, as escolhas, as doses e medidas, enfim, a mão de quem cozinha, seremos levados a admitir a existência de uma dimensão corporal paralela e até mesmo autônoma no processo. De modo semelhante, a escrita: pode-se sempre escrever tendo uma ação exterior como fim, escrever para cumprir uma exigência, modificar uma percepção a respeito de algo, emitir uma opinião sobre determinado assunto. Mesmo nesses casos, em que o escrever se encerra juntamente com o final da atividade na qual sua existência estava inscrita, o tempo próprio de sua realização é marcado por um número incontável de seleções, escolhas e recusas, opções de estilo. No ato de escrever - assim como no ato de ler - há sempre um corpo trabalhando a seu modo, dando o tom e ditando o ritmo.

Há, nesses atos, um meio próprio que permanece imune aos efeitos do antes e depois. Um meio que age em suspenso, de modo imperceptível, regulando o tempo e a atmosfera de ação. É esse o meio dos gestos.

Mesmo que de modo descontínuo, o gesto constitui um ponto central no pensamento de Agamben. No recente Por uma ontologia e uma política do gesto, a pergunta "o que é o gesto?" é respondida da seguinte maneira: “[...] o gesto não é nem um meio, nem um fim: antes, é a exibição 
de uma pura medialidade, o tornar visível um meio enquanto tal, em sua emancipação de toda finalidade" (AGAMBEN, 2018, p. 3).

A imagem do gesto como uma medialidade sem fim é, nesse sentido, necessariamente ativa, já que interrompe a relação do corpo com toda finalidade exterior a ele próprio. Ao invés de uma negatividade ou de uma ação mecânica, o gesto é afirmado como ato poético: "[...] cada corpo, uma vez liberado da ação voluntária com um fim, seja orgânico ou social, pode [...] explorar, sondar e mostrar todas as possibilidades de que é capaz" (AGAMBEN, 2018, p. 6). Quando afirma que a modernidade foi a época na qual a sociedade perdeu-se de seus gestos, Agamben (2008, p. 11) certamente está considerando o automatismo, a mecanização e a aceleração que são marcas centrais desse tempo. No lugar dos gestos, “[...] enquanto ações de potências invisíveis", e vitais, a sintomatologia moderna inclui a exteriorização da força, a reação automática a estímulos de toda ordem, o embrutecimento do corpo.

Dentro da obra de Agamben, a natureza do gesto é sempre pensada em sua relação com o tempo, sendo que o aparecimento do gesto determina um momento de interrupção e suspensão na sucessão cronológica linear. A imagem com a qual tal ideia é sustentada está presente no tratado Dell'arte di ballare e danzare, de Domenico da Piacenza, coreógrafo do século XV. Na obra, Agamben (2018, p. 3) encontra o fantasmata, momento de pausa súbita entre os movimentos na dança, “[...] a ponto de contrair na própria imóvel e petrificada tensão a medida e a memória de toda série coreográfica". Defendido no tratado como um dos elementos fundamentais da dança, o fantasmata faz do dançar um gesto caracterizado pela organização serial de imagens passadas no espaço e no tempo. Conduzida pela memória, a dança funcionaria como um assombro contínuo, o gesto do fantasma que paralisa e simultaneamente move o corpo.

Enquanto o espaço é o lugar dos atos, o tempo desempenha o papel central no "estado de dança" (VALÉRY, 2013, p. 36), uma vez que o lugar de quem dança é precisamente essa pausa não imóvel, a cabeça de medusa que sustenta em sua imagem a memória paralisante que prepara o próximo movimento.

Parece-nos que é possível pensar o gesto à luz da noção de "forma breve", tal como a noção é proposta por Barthes (2005, p. 150). Em um gesto, “[...] tudo é dado imediatamente", de modo que ele não pode se desenvolver, ser acrescido de nada, em suma, não há como estendê-lo. O gesto é uma autoridade pura, que não precisa buscar autorização em coisa alguma. Sua criação e sustentação já constituem sua legitimação, e esta reside na abertura de um espaço onde um movimento livre de automatismos se torna possível. A imagem desse espaço é a reunião de vários tempos heterogêneos, já que o gesto é justamente esse recorte temporal que sobrevive enquanto potência fantasmática (DIDI-HUBERMAN, 2013).

Voltemos a Warhol, e destaquemos em sua obra uma outra realização que nos será útil.

Filmados entre os anos de 1963 e 1966, os Screen tests são retratos cinematográficos feitos com centenas de personagens, cuja única atribuição consistia em suportar um filme sem nenhum roteiro a ser representado, sem nenhum texto, nenhuma orientação. Como em um mugshot, Warhol capta seus personagens em primeiro plano, em tomada única, durante alguns minutos. $\mathrm{O}$ alto contraste da fotografia em preto e branco faz com que a pele se projete sobre o fundo escuro com nitidez, tornando claro o propósito de desnudamento da ação. O cinema é aqui pensado como dispositivo de desmontagem da pose e desvelamento do corpo. O artista movimenta-se pela superfície, interessa-se pelo detalhe, está à espreita do não previsto. Ele busca o gesto. E por ele espera. 
Quando Agamben se aproxima de Marco Terrêncio Varrão e de sua obra De lingua latina, ele encontra a indicação de três "graus" possíveis da atividade humana, denominadas facere, agere e gerere. "Pode-se", escreve Agamben (2018, p. 2), citando Varrão:

[...] fazer (facere) algo e não agir (agere), como o poeta que faz um drama, mas não o age [agere significa também "recitar"]; ao contrário, o ator (actor) age um drama, mas não o faz. Assim, o drama é feito pelo poeta, mas não é agido, enquanto pelo ator é agido, mas não feito. Pelo contrário, o imperator [o magistrado munido do poder supremo, o imperium], que se diz res gerere, com este não faz nem age, mas gerit, isto é, sustenta (sustinet), expressão traduzida por aqueles que carregam um peso [ou, segundo outros códigos, investem-se num cargo].

Como terceiro gênero de ação, o gesto distingue-se do fazer e do agir, situando-se entre ambos. Termo derivado etimologicamente do gênero gerere, ele é um meio sem fim. "O gesto rompe a falsa alternativa entre fins e meios que paralisa a moral, e apresenta meios que, como tais, se subtraem, ao âmbito da medialidade, sem por isso tornarem-se fins" (AGAMBEN, 2008, p. 13).

Derivada de Aristóteles, em Ética a Nicômaco, a distinção entre facere e agere, tal como destaca Agamben, está relacionada à oposição entre a ação (praxis) e a produção, o fazer (poiesis). Enquanto o fim do fazer está relacionado ao fazer aparecer, ou seja, é algo diferente do próprio fazer, o fim da praxis não pode ser outro que não ela própria, isto é, trata-se de uma vontade que se exprime de modo imediato na ação.

O gesto, portanto, constitui um tipo de ação humana que não pode ser explicada apenas pelo agir ou pelo fazer. Enquanto o agir remete à própria ação em si, constituindo-se uma finalidade em si mesma, e o fazer se endereça a um fim que lhe é exterior, o gesto é pura medialidade, uma ação que só exibe a si própria. Não sendo nem um meio para um fim, nem um fim sem um meio, o que constitui um gesto e o que ele comunica é o próprio sustentar, o suster, o assumir. Tornar visível o meio onde isso se dá constitui sua plasticidade, e é apenas em termos de desejo que sua existência pode ser dimensionada. Um gesto simplesmente quer ser.

É particularmente interessante, nesse sentido, o Screen test de Ann Buchanan, batizado de Ann, the girl who cries a tear. O plano sequência tem a duração de 4'20". Ela permanece imóvel, olhando fixamente para a câmera, sem piscar. Não há som, apenas um rosto que encara a objetiva. A pose de Ann dispõe tempos mortos em sequência. A seu modo, realiza uma tanatografia particular (DUBOIS, 1993), sua íntima escrita da morte. O devir-fantasma que assistimos, enquanto espectadores, manifesta-se de forma mais evidente a partir da segunda metade do vídeo. Mantidos abertos, os olhos choram, uma lágrima é derramada, a garganta engasga.

Há uma dupla sustentação em cena. De um lado, o artista conduz e registra. De outro, o corpo, frame a frame, vai de desfazendo de sua pose.

Talvez, ao invés de pensar o gesto como um movimento, mais preciso seja entendê-lo como a abertura de um espaço onde algum movimento não antecipado possa acontecer. Há sempre uma imprevisibilidade em causa, uma vez que não há nenhum fim em jogo. Não há nada para além do gesto que ainda possa ser considerado gesto. Entre a dualidade dos fins e dos meios, situamo-nos aquém e além de todo resultado, em um plano de gestualidade integral.

O gesto de chorar, uma lágrima que cai, é um "efeito de real" (BARTHES, 2005, p. 143), ou seja, uma legibilidade garantida pelo desvanecimento de todo recurso, de todo artifício, de toda linguagem. Quando Ann chora, a lágrima deixa a nu aquilo que o vídeo pretende mostrar. O gesto atesta a realidade do corpo, o real que se demonstra em meio a toda produção da aparência. 
Abrir um espaço e nele expressar algo que a razão não poderia prever e articular: não é esse, justamente, o gesto artístico? E, arrisquemos, não seria esse o corte a partir do qual o gesto docente, em sua especificidade, aproxima-se da estética?

Pensar o gesto em relação ao corpo, por meio de sua relação com outros corpos, ou seja, através de seus efeitos, é o que permite afastá-lo da abstração. Porque o gesto é “[...] um movimento do corpo que está investido de certa capacidade de significado ou de expressão" (DIDIHUBERMAN, 2007, p. 19). A potência de cada gesto reside em seu chamado, na maneira como o meio que ele articula atrai outros corpos, afeta-os, delineia uma relação. Se é a esfera do gesto - e não a da ação -, tal como sugere Agamben (2018, p. 6), a privilegiada para pensar a ética e a política, isso se dá porque a atividade própria do gesto é a ação encenada por corpos livres.

\section{UM LUGAR SUSPENSO, ENFIM}

“Gesto-opinião" é o termo que Barthes (2009, p. 259) encontra na obra de Philippe Sollers, e com o qual sugere um tipo particular de experiência do saber, norteada pelo corpo. Em linhas gerais, trata-se de uma experiência apartada da cultura, e que por isso não pode ser pautada pela busca do sentido e interpretação, mas apenas pelo afeto. Amostras desses "[...] movimentos corporais apropriados" são dadas por Barthes em diferentes momentos de sua obra, nos quais o corpo é o mediador de encontros com signos fotográficos, musicais, literários, entre outros.

Esse corpo que acompanha um ato expressivo não por um movimento de saber ou mesmo emoção, mas sim pelos gestos que ele, a seu tempo, produz, é a imagem com a qual encaminhamos o encerramento deste ensaio.

Porque o gesto-opinião é o gesto próprio do corpo que está suscetível à proximidade e à interferência do outro.

Se, pelo princípio formativo comum que aqui defendemos, o que está em jogo em uma aula não é seu caráter instrumental, mas sim o que pode haver nela de potencialidade, então a efetividade da relação pedagógica não se encontra no campo do decifrável. Em uma aula, produz-se em meio aos signos, pela potência do indizível, na materialidade intensiva dos encontros.

Lugar do gesto, a aula é o tempo da demora, das ações que não são meios para nada, e que tampouco são seus próprios fins. Há sempre um endereçamento, mesmo que impensado. Um gesto participa do jeito de fazer, do modo de dizer, escutar, deixar circular o saber. Um gesto é um meio no qual há a pausa para a pesquisa, para os exercícios sobre si mesmo, diante ou distante do outro, um meio no qual são postos em cena o desejo e o pensamento.

É sua suspensão, pois, que atrai e lisonjeia. Coletividade à parte em meio ao mundo, não é a aula, por excelência, o potencial lugar suspenso, a ser sempre reafirmado, reinstaurado, em suma, re-gesticulado? "Ele acontece a cada semana, bem ou mal, levado pelo mundo que o cerca, mas também resistindo a ele, assumindo suavemente a imoralidade de uma fissura da totalidade que aparta por todos os lados" (BARTHES, 2014a, p. 423). Nesse meio, temos o direito momentâneo à não-comunicação, à não-transmissão, ao não-gregarismo.

Que a imoralidade seja, enfim, desdobrada em moralidade do gesto. A moral própria de um corpo livre e superficial, no qual a liberdade é inscrita em meio a outros corpos. Nenhuma lei a não ser a lei dos encontros, nenhum tempo a não ser o tempo de sua realização.

Assim sustentada, uma aula - simplesmente - acontece...

\section{REFERÊNCIAS}


AGAMBEN, Giorgio. Notas sobre o gesto. Artefilosofia, Ouro Preto, n. 4, p. 9-14, jan. 2008.

AGAMBEN, Giorgio. Por uma ontologia e uma politica do gesto. Belo Horizonte: Chão de Feira, 2018.

AGAMBEN, Giorgio. Réquiem para os estudantes. São Paulo: n-1 edições, 2020. Disponível em https://n-1edicoes.org/082. Acesso em 2 ago. 2020.

AQUINO, Julio Groppa. Diálogos em delay: especulações em torno de uma temporalidade outra do encontro pedagógico. Educaşão e Pesquisa, São Paulo, v. 43, n. 2, p. 311-326, abr.-jun. 2017.

AQUINO, Julio Groppa. Educação pelo arquivo: ensinar, pesquisar, escrever com Foucault. São Paulo: Intermeios, 2019.

AQUINO, Julio Groppa; CORAZZA, Sandra Mara; ADO, Máximo Daniel Lamela. Por alguma poética na docência. Educação em Revista, Belo Horizonte, v. 34, jan. 2018.

ARENDT, Hannah. Entre o passado e o futuro. São Paulo: Perspectiva, 1979.

BARTHES, Roland. A câmara clara. Rio de Janeiro: Nova Fronteira, 1984.

BARTHES, Roland. O rumor da lingua. São Paulo: Martins Fontes, 2004a.

BARTHES, Roland. O grão da vo\%: São Paulo: Martins Fontes, 2004b.

BARTHES, Roland. A preparação do romance I. São Paulo: Martins Fontes, 2005.

BARTHES, Roland. O óbvio e o obtuso. Lisboa: Edições 70, 2009.

BENJAMIN, Walter. Magia e técnica, arte e política. São Paulo: Brasiliense, 1994.

CORAZZA, Sandra Mara. Pedagogia dos sentidos: a infância informe no método Valéry-Deleuze. In: KOHAN, Walter Omar (org.). Devir-Criança da Filosofia: in-fância da educação. Belo Horizonte: Autêntica, 2012, p. 81-94.

DARDOT, Pierre; LAVAL, Christian. Comum: ensaio sobre a revolução no século XXI. São Paulo: Boitempo, 2017.

DIDI-HUBERMAN, Georges. Um conocimiento por el montaje. Ed. Minerva, 2007. Disponível em http://www.circulobellasartes.com/fich minerva articulos/Un por el montaje (4833).pdf. Acesso em 1 ago. 2020.

DIDI-HUBERMAN, Georges. A imagem sobrevivente. História da arte e tempo dos fantasmas segundo Aby Warburg. Rio de Janeiro: Contraponto, 2013.

DUBOIS, Philippe. O ato fotográfico. Campinas: Papirus, 1993.

FLUSSER, Vilém. Gestos. São Paulo: Annablume, 2014.

HAN, Byung-Chul. Agonia do Eros. Petrópolis: Vozes, 2017.

HOOKS, bell. Ensinando a transgredir. a educação como prática de liberdade. São Paulo: Martins Fontes, 2017.

LISPECTOR, Clarice. Água viva. São Paulo: Rocco, 1998.

MATOS, Olgaria. Dialética na imobilidade da mens momentânea à imobilidade do instante. In: NOVAES, Adauto (org.). O futuro não é mais o que era. São Paulo: Ed. Sesc SP, 2013, p. 103-132.

NÓVOA, António. Os professores e a sua formação num tempo de metamorfose da escola. Educaşão e Realidade, Porto Alegre, v. 44, n. 3, set. 2019.

PENNAC, Daniel. Como um romance. São Paulo: Rocco, 1993.

PISETTA, Écio Elvis. Natalidade e educação. Revista Teias, Rio de Janeiro, v. 20, n. 58, jul./set. 2019. 
REY, Jean-Michel. Valéry, os exercícios do espírito. In: NOVAES, Adauto (org.). Artepensamento. São Paulo: Companhia das letras, 1994, p. 149-161.

SANTAELLA, Lucia. Linguagens líquidas na era da mobilidade. São Paulo: Paulus, 2007.

VALÉRY, Paul. Variedades. São Paulo: Iluminuras, 1998.

VALÉRY, Paul. Degas Dança Desenho. São Paulo: Cosac \& Naify, 2013.

WARHOL, Andy; HACKETT, Pat. POPism: The Warhol Sixties. Londres: Penguim Books, 1980. WOOLF, Virginia. Contos completos. São Paulo: Cosac \& Naify, 2008.

ZORDAN, Paola; ALMEIDA, Verônica Domingues. Parar pandêmico. Práxis Educativa, Ponta Grossa, v. 15, p. 1-18, jul. 2020.

\section{Informações dos autores}

Cristiano Bedin da Costa

Universidade Federal do Rio Grande do Sul (FACED-UFRGS)

E-mail: cristianobedindacosta@gmail.com

ORCID: http://orcid.org/0000-0003-0935-8503

Link Lattes: http://lattes.cnpq.br/1830829812319182

Angélica Vier Munhoz

Universidade do Vale do Taquari (UNIVATES)

E-mail: angelicavmunhoz@gmail.com

ORCID: http://orcid.org/0000-0002-2644-043X

Link Lattes: http://lattes.cnpq.br/4928481211980742 